\title{
Archipel
}

ARCHIPEL Études interdisciplinaires sur le monde insulindien

102 | 2021

Varia

\section{"I'm a child of Lee Kuan Yew, cannot help it": Students' narratives on language and ethnic planning in Singapore}

"I'm a child of Lee Kuan Yew, cannot help it": discours d'étudiants sur le planning ethnique et linguistique à Singapour

\section{Gilles Forlot}

\section{OpenEdition}

\section{Journals}

Édition électronique

URL : https://journals.openedition.org/archipel/2629

DOI : 10.4000/archipel.2629

ISSN : 2104-3655

\section{Éditeur}

Association Archipel

\section{Édition imprimée}

Date de publication : 31 December 2021

Pagination : $99-127$

ISBN : 978-2-910513-87-0

ISSN : 0044-8613

\section{Référence électronique}

Gilles Forlot, " "I'm a child of Lee Kuan Yew, cannot help it": Students' narratives on language and ethnic planning in Singapore », Archipel [En ligne], 102 | 2021, mis en ligne le 15 décembre 2021, consulté le 15 décembre 2021. URL : http://journals.openedition.org/archipel/2629; DOI : https://doi.org/

10.4000/archipel.2629 
GILLES FORLOT *

\section{"I'm a child of Lee Kuan Yew, cannot help it": Students' narratives on language and ethnic planning in Singapore}

This article examines the perceptions of young educated Singaporeans on their country's language policies and their own linguistic practices. The overall fieldwork ${ }^{1}$ the research is based on comprises 630 on-line-administered questionnaires, a series of 31 semi-structured students' interviews carried out between 2016 and 2018 as well as a thirteen interviews of local teachers, university scholars and cultural and community figures in Singapore.

This contribution focuses on the student population of our $^{2}$ research, which constitues the ethnographic and qualitative part of the project. The central objective of this text is to analyze the somewhat ambivalent discourses that these social actors engage in when it comes to discussing the language policies implemented by their elders. In Singapore, language issues are intrinsically intertwined with social and political issues. Increased criticism has risen towards language policies that were premised on simplistic ethnocultural views, the necessity of common, homogeneous languages, and a quest for an even greater recognition of

* INALCO, SeDyL - UMR CNRS 8202.

1. I am grateful to the Sorbonne Paris Cité Consortium and the National University of Singapore for co-financing two research grants (LASIPA 2015 and CoLaSeA 2017) which made this fieldwork possible.

2. The choice between ' $\mathrm{I} / \mathrm{my}$ ' and 'we/our' in this article has to do with the fact that a large part of the fieldwork was organized and carried out with the collaboration of my colleague Daniel Kwang Guan Chan of the National University of Singapore. I am indebted not only to his help, but also to his fine knowledge of the sociolinguistic situation of the city-state and to the many discussions we continue to have on Singapore's social life. 
ethnolinguistic diversity in Singapore has emerged (Jain \& Wee 2018). The choice of English for everyone and of Mandarin for the Chinese community were clearly linked to prestige planning (Curdt-Christiansen 2014). Prestige planning is the process whereby each language is positioned in a given society according to its status, its image and the self-perception of its speakers (Ager 2005).

After providing an overview of Singapore language policies in the past sixty years, I will present the corpus at hand and show how it can contribute to understanding the complexity of discourses on language diversity in the Southeast Asian city-state. The article shows that these elite Singaporean students harbour feelings that range from acceptance and legitimization of the choices made by their elders to resentment for creating artificial and essentialist categories which led to language loss, language shift and communicative barriers. Furthermore, these youths' discourses reveal that they are well aware of the ways languages and ethnicities have been commodified and instrumentalized towards both the manufacturing of the state and its national narrative. I will also show how some of these elite students of Chinese extraction position themselves critically vis-à-vis the homogeneous Chineseness that was engineered through the post-independence Mandarinonly policy known as the "Speak Mandarin Campaign."

One of the decisive elements in the aftermath of the birth of the Republic of Singapore was the management of its survival via its social and ethnic cohesiveness as well as its economic development. The first governments developed a sort of dual ideology, whereby preserving the city-state's ancestral Asian identity and fostering the link to globalization and the market economy had to be undergirded in a policy of official bilingualism. Listening to those youths' narratives unveils to what extent they are aware that languages have always been instrumentalized (Wee 2003) as means towards the building and survival of the state, and therefore as tools of social control in this late authoritarian form of governmentality (George 2007; Liew 2015).

\section{Introductory remarks}

\section{Survival as an independent nation in late modernity}

Modernity is the historical period marked by industrialization and the stabilization of nation-states, mostly in the 19th century. With the rise of more fluid social structures, increased mobility, and the advent of globalization, the subsequent period is often referred to as late or high modernity (Giddens 1990). Singapore is an interesting case insofar as its constitution as an independent republic also coincides with the rise of late modernity, and the establishment of a nation-state that had to cope with an already existing high diversity. As Heller et al. (2016: 3) note, "we are now emerging from a long period where the nation-state has been presumed to be the only normal way to organize ourselves as populations and territories." 
Within this late-modern framework, languages play a key role, as they are now being revalued as skills and commodities (Da Silva et al. 2007). Late modernity has created the conditions of a disentanglement of languages and identities seen as essential and authentic attributes of people themselves (Stroud \& Wee 2012: 38-39), or at least the possibility for challenging such modernist views in acts and discourses and conceiving languages and identities as products, resources and consumption goods.

In 1965, following their separation from the Federation of Malaysia after several years of tensions with Kuala Lumpur (Turnbull 2009: 287-293), the People's Action Party leaders of the newly proclaimed republic set about the difficult task of bringing independent Singapore to life. The task was daunting, given the lack of natural resources and infrastructure. Founding Prime Minister Lee Kuan Yew's first goals for survival were to modernize the island, to provide it with a viable industry, a deterrent defence force, social and educational progress, and international recognition.

The ruling party thus adhered to "a vigorous economic development orientation" ideology (Chua 1995: 59) and set out another strong priority: that of social cohesion on this multicultural island, whose population comprised various groups, mostly the Chinese, the Malays, and the Indians, as well as a minority of Eurasians and other residents. ${ }^{3}$ This cohesiveness therefore required both the development of a national education system, access to employment and the massive construction of social housing from the 1970s on.

\section{Foundational languages policies}

In terms of language management, the leaders of the Singaporean state opted for a policy of bilingual learning, later conceptualized by Pakir (1992) as "English-knowing bilingualism." English, as the language of Western economic development, became the medium of instruction, and the maintenance of Asian identities was engineered by imposing the learning of one of the three official languages other than English on the citizenry. This Bilingualism Policy (1966) derived from the formal education introduced in the late 1950s on the island at the time of its emancipation from the British colonial rule (Bolton \& Ng 2014). Two years after independence, in 1967, the Singaporean government closed Malay, Chinese and Tamil language schools under the pretext of declining attendance (Tan 2007) to generalize English as the language of schooling.

Bolton and $\mathrm{Ng}$ (2014: 309) point out how radical this change was, insofar as the use of English, in accordance with the British colonial tradition, had until

3. The ethnic composition of Singapore has been fairly stable since the 1950s. In 1957, the Chinese, the Malays, the Indians and the residents in the 'Others' category respectively made up $75.4 \%, 13.6 \%, 8.6 \%$ and $2.4 \%$ of the total population. In 2015 , the figures were $74.3 \%, 13.3 \%, 9.1 \%$ and $3.3 \%$. These figures are those of the Singapore Departement of Statistics, cited in Ng \& Cavallaro (2019). 
then been mostly restricted to the administration. On a daily basis, vernacular - and sometimes hybrid - languages, such as Bazaar Malay and Hokkien, served as inter-ethnic lingua francas. Within the various communities and districts of the island, residents spoke their ethnic languages and many had advanced skills in several extra/inter-community languages (Platt et al. 1980).

It is virtually impossible to speak about Singapore's languages without describing the place of English in the island's postcolonial history and appreciating how the fate of this language has interacted with those of the local communities. Singapore was a British territory from 1819 to 1955 and English was the administrative language of the colonial rulers, but locally, each community language remained dominant, and their members were often multilingual. The figures from the 1957 census are telling. Only $1.8 \%$ of the island's inhabitants spoke English and $0.1 \%$ of the Chinese inhabitants were native Mandarin speakers, while Malay - in various forms, including the local Peranakan Malay and Bazaar Malay - was spoken by $48 \%$ of the total population. It is worth noting that in those times, a third of the Chinese population and some $88 \%$ of the Indian population were proficient in Malay as well (Bolton \& Ng 2014: 308). The reality of colonial Singapore was therefore that of multilingual practices.

Soon after independence, the Singapore government actively addressed the issue of languages, opting for four official ones: English, the language of the colonizer, Chinese (labeled as Mandarin), Tamil and Malay. One of the initial ideas of the Singaporean leaders was to create a crossroads between the East and the West, and Lee Kuan Yew championed the essentialist idea that its citizens must learn both English, the language of growing globalization, while maintaining the link to their Asian roots, in particular by learning the language of their presumed homogeneous community (Jain and Wee 2018), i.e. Mandarin for the Chinese, Malay for the Malays and, in the first decades after independence, Tamil for the Indians. Thus, the authorities opted for a "simplified, multiracial CMIO (Chinese, Malay, Indian, Others) quadranomy" (Siddique 1990: 36). In 1990, acknowledging the diversity of the Indian community, the Government opened the door for more South Asian languages officially taught as Mother Tongues, i.e. Bengali, Gujarati, Hindi, Punjabi and Urdu (see Jain \& Wee 2017; Jain 2021 for details on the Indian community).

English thus became the mainstream language of instruction until university, but all citizens - with the exception of Eurasians and Permanent Residents - were commanded to learn the Asian language of their identified communities. When decreeing the official and mandatory learning of English, the Government set out two main objectives. The first one was to reach out to the world of developed, industrialized nations, already dominated by the Anglo-American capitalist model, with English assuming the role of the language of trade and mobility of people and resources. The second objective was to promote English as the 
neutral language, thus forstering both the internal cohesion of the country and the emerging economic globalization where business was now conducted in English.

Malay, Mandarin and Indian languages for their part took on the status of ethnic, cultural, and family languages, with the purpose of reinforcing Asianness, even if in the case of Mandarin, the Government was well aware that standard Chinese was to become an instrument of development as well. Ever since this policy was implemented and to make it function equitably and ensure neutrality, Singaporean policy makers have always contended that English could not become a "Mother Tongue" (Wee 2002; Lim et al. 2010: 6; Tan 2014).

The state sought to create a division of labour between languages, assigning to each language its roles and functions (Stroud \& Wee 2012: 28-32). A double division of labour, as it were: English was restricted to interethnic communication and became the tool of economic competitiveness on a global scale, while heritage languages were kept within their respective communities to foster intra-ethnic solidarity and to enhance a supposed link to Asian values and ethnicity. But since each heritage language was expected to be catering to its assigned ethnicity, a neat separation - and strict recognition of equal status - between the communities was reinforced. The Government therefore embraced an ideologically monolingual stance (ibid.), as each language was meant to assume specific, compartmentalized functions.

Since its advent as an official language in Singapore, English has been performing functions that prevent it from becoming a "Mother Tongue", as mentioned supra. As a commodified instrument of inter-ethnic communication, it is meant to secure the unity of the nation. However, English is also a class language, since its standard version and the popular, colloquial variety known as Singlish do not fulfill the same functions or enjoy the same prestige (Stroud $\&$ Wee 2007). Nor do all Singaporeans have access to the more prestigious forms (Wee 2018) that are supposed to turn them into legitimate, authorized speakers on a competitive job market (Bourdieu 1991). All these questions contribute to feeding the often heated debate and controversies about the status of Singlish in Singapore (Cavallaro \& Ng 2009; Tan 2017; Wee 2018).

\section{Revamping language policy and practice: prestige planning for a new nation}

As expounded above, becoming an independent state required some re-organisation of the local language practices and ethnic distribution, a sort of re-landscaping, as it were. Three campaigns are important in understanding language policies in Singapore. The first one, described above, is the Bilingualism Policy of 1966.

Another significant moment came in 1979. So as to foster the teaching and learning of Mandarin and engineer the conversion of the Singapore majority population of Chinese descent, the Government initiated a yearly campaign for the promotion of Mandarin at all stages of society (and not only at school, 
where it had been compulsory for more than a decade): the Speak Mandarin Campaign (Lee 2011; Ng 2017), hereafter referred to as SMC. The objectives of the SMC, as officially expounded by the Government, were educational, communicative, and cultural (Bokhorst-Heng 1998; 1999). It was believed that the learning of Mandarin could be sped up if Chinese dialects ${ }^{4}$, i.e. Hokkien, Cantonese, Teochew, Hainanese, Hakka and several others, were set aside in the public space, banned from the media, evacuated from the educational sphere and if their use was discouraged in family interactions.

The insistance on standard linguistic practices in English and Mandarin brings to light the state's obsession with prestige planning (Lim 2009). In a letter published in the national daily newspaper The Straits Times on March 7, 2009, Chee Hong Tat, the Principal Secretary of Minister Mentor Lee Kuan Yew provided the following explanation for this move:

"This is why we have discouraged the use of dialects. It interferes with the learning of Mandarin and English. Singaporeans have to master English. It is our common working language and the language which connects us with the world. We also emphasised the learning of Mandarin, to make it the mother tongue for all Chinese Singaporeans, regardless of their dialect groups. This is the common language of the 1.3 billion people in China. To engage China, overseas Chinese and foreigners are learning Mandarin and not the dialects of the different Chinese provinces. (...) That was the reason the Government stopped all dialect programmes on radio and television after 1979. Not to give conflicting signals, then Prime Minister Lee Kuan Yew also stopped making speeches in Hokkien, which he had become fluent in after frequent use since 1961." 5

The educational argument was based on the assumption that vernaculars were a hindrance to the development of Mandarin, which as pointed out by several scholars (Gupta 2008; Chew 2013) was seldom a home or ancestral language of the Chinese community when the country became independent. Recent demographic surveys (Wong 2011; Leimgruber 2013: 6-8) and research on language use and practices (Vaish et al. 2009; Siemund et al. 2014; Leimgruber et al. 2018; Forlot \& Chan 2017) show that some of these - mostly Southern Chinese vernaculars are still in use, albeit on the decline, and ethnographic research on the field ( $\mathrm{Ng} \mathrm{2017)}$ or online (Tan 2012) also demonstrates an explicit attachment to these family languages, as I will show below.

The major argument of the SMC was that the number of vernaculars still in use in 1979 was seen as a barrier to Chinese intra-ethnic intelligibility and sense of belonging. Mandarin was then to be adopted as a common language,

4. I chose to retain the term 'dialect' in this article, along with the term 'vernacular.' Leimgruber (2013: 3) reminds us that the word 'dialect' is used both by scholars in the field and Singaporeans themselves to refer to the different varieties of Chinese.

5. https://www.asiaone.com/News/Education/Story/A1Story20090311-127699.html; originally published in the Straits Times, March 7, 2009. Last accessed February 18, 2021. 
thus addressing as well the cultural argument of the SMC: promoting the preservation and development of Asian values, which were viewed as endangered in light of the increasing Westernization of the country (Ho \& Alsagoff 1998). Mandarin was expected to serve both as a tool of unification and as a cultural ballast (Tan 2007: 81) against a perceptibly bad effect of Westernization. So were the other Mother Tongues, as retired, founding Prime Minister Lee Kuan Yew clearly expressed in 2012:

"I stressed the importance of Mandarin to Chinese Singaporeans. Not only was using dialects an obstacle to learning Mandarin and English in schools, it would displace Mandarin and strengthen the position of English. (...) Mandarin is emotionally acceptable as our mother tongue (and Malay and Tamil for the other ethnic groups)" (Lee 2012: 150)

Understanding the recent sociolinguistic history of Singapore requires to look at the bigger picture. The elements of the language debate - as shown in the fieldwork I will present infra-include both local, colonial and international languages. In most multicultural and multilingual spaces, whether colonized or not, human contacts have the effect of transforming language practices and adapting them to local realities. Singapore is no exception.

Before the inception of colonial rule (1819), the islanders already exchanged in linguistic forms that they hybridized according to their needs, mostly in Bazaar Malay or in a local, indigenous form of English which still reflects the contacts of the people who speak it (Chew 2013; Leimgruber 2013). Singapore English, and in particular its colloquial forms (popularized under the name of Singlish) can be identified through some features, such as an English-based grammar, a lexical contribution and some morphosyntactic characteristics deriving from Malay and Chinese vernaculars like Hokkien, Cantonese and Teochew. These flexible linguistic forms adapt to circumstances, evolve in history and constitute a continuum between a so-called standard English and strongly hybridized forms of speech.

In 2000, an annual campaign of normative and prescriptive promotion was launched for English - the Speak Good English Movement (henceforth SGEM). The purpose was to promote the learning and practice of a Britishinspired international English. Right from the outset, the SGEM campaign also aimed at ostracizing the linguistic forms associated with Singlish, reinforcing the image of language impurity and incorrectness it already had (Rubdy 2001). Former Prime Minister Lee Kuan Yew even branded it as "a handicap we must not wish on Singaporeans" (see quotation below).

The two campaigns are well described by the man who was at the source of their engineering, Lee Kuan Yew. Note how he takes personal responsability in these foundational language policies by resorting not only to a collective "we" (i.e. Singapore as a society, led by the ruling People's Action Party), but also to the "I" personal pronoun in this excerpt: 
"Let me tell you what we did about Mandarin. Twenty five years ago, we decided that we would not speak a special Singapore Mandarin, pronounced with Hokkien, Teochew or Cantonese accents, and with Malay words thrown in. To set the standard, I had our announcers on radio and television and school teachers retrained by teachers from Taiwan who spoke standard Mandarin. We also hired a few announcers for TV and radio from Taiwan to set the pace. Because we used standard Mandarin on TV, radio, and with teachers in schools, we now have a generation of young Singaporeans able to speak more of a standard Mandarin. The Chinese-speaking world outside Singapore can understand us.

We must take the same approach with English. Get our teachers retrained. Do not popularise Singlish. Do not use Singlish in our TV sitcoms, except for humorous bits, and in a way that makes people want to speak standard English. We will see a difference in another one generation. The people who will benefit most are those who can only master one kind of English. Singlish is a handicap we must not wish on Singaporeans." 6

\section{Analyzing language practices, attitudes and discourses}

\section{The contribution of quantitative investigations}

Studying attitudes towards languages has a long scholarly tradition in sociolinguistics and psycholinguistics. Labov's pioneering research on the social stratification of English resorted mostly to methodological tools involving language perceptions. In the 1970s and 1980s, a number of research led by social psychologists of language sought to study the linguistic and communicative features of intergroup relations, the linguistic dimensions of identity constructions. Most of this scholarly research has tapped on the notion of attitudes, focusing "on a variety of groups and intergroup processes, including gender, age, ethnicity, and institutional role" (Weatherall et al. 2007: 2-3). These approaches have relied on quantitative and/or experimental methodological instruments such as questionnaires, surveys and verbal guise and matched-guised techniques uncovering the way people perceive the speech of others or the way they think people perceive their own way of speaking.

Probably because of its multicultural and multilingual fabric, Singapore has attracted language scholars both from within and from around the world, be they formal linguists, language educationists, sociolinguists, anthropologists or psycholinguists. It is easy nowadays to have access to a large body of scholarly literature on language practices, policies and attitudes, most of which is published in English. Research on attitudes and beliefs gained popularity in the 2000s, aiming at describing attitudes towards standard English and Singlish (Cavallaro \& Ng 2009; Tan 2017, amongst others), towards varieties of Mandarin Chinese (Wong \& Tan 2017a) or towards the accent production of

6. Speech by Senior Minister Lee Kuan Yew at the 34th National Day Celebration, August 14, 1999, Tanjong Pagar Community Club. Source: https://www.nas.gov.sg/ archivesonline/data/pdfdoc/1999081404.htm. Last accessed on February 10, 2021. 
speakers and their possible ethnic identification (see Cavallaro \& Serwe 2010 or Sim 2019 on the Singapore Malay population). Some of these publications show the attachment of speakers to their family languages, including Singlish. What is also highlighted is the fact that the two language promotion campaigns (SMC and SGEM) have taken their toll, as English is spreading in daily use and generally produces positive attitudes.

A number of these quantitative investigations deal with the issues of the Mandarinization of the Chinese community and the slow language shift towards English which all communities experience in the city-state. What is often studied is the attitudes and feelings of the respondents towards their assigned languages and/or their ethnic communities. Kamwangamalu (1992) for instance showed that almost all of his participants felt that Chinese was "their" language (as in native language), but that less that half (38\%) felt that their feelings for it was very high, thus demonstrating a growing sense of Singaporeanness and a detachment of the language from the ethnic affilation it is supposed to convey. Wong and Tan (2017a), partially drawing on drawing on Kamwangamalu (1992)'s interpretations, come to the conclusion that what is valued mostly by Chinese Singaporeans is the instrumental value of mandarin, and not (or no longer) the ethnicity the authorities have been trying to sustain. These results concur with Wee (2003)'s or Tupas (2015)'s analysis of how language policy in Singapore has been hinged on a high level of pragmatism (Wong \& Tan 2017a: 40).

In terms of status and solidarity, various investigations were carried out to uncover the attitudes of Singaporeans towards their community languages. For instance, $\mathrm{Xu}$ et al. (1998) concluded that while English was identified by the respondents as a powerful and prestigious language, Mandarin was rated as high in solidarity. In light of these studies and with regard to the steady increase of Mainland Chinese migration to Singapore between 1990 and 2015, Cavallaro et al. (2018) studied attitudes towards the different Mandarin varieties within a group of Singaporean Chinese and a group of Mainland Chinese nationals living in Singapore. Their study demonstrates that both groups assign a higher status to the variety of Chinese spoken in mainland China, and that Singaporean participants favoured the standard variety - probably a by-product of the school education - while PRC nationals preferred the colloquial variety of the language.

What some studies have confirmed statistically as well is the impact of the Speak Mandarin Campaign not only on daily use, but also on the attitudes of social actors. For instance, Wong and Tan's (2017a \& 2017b) quantitative results show that though considered important for identity construction, Chinese dialects in Singapore have been clearly marginalized, with low rates of daily use, except maybe in the family domain and mostly with the elders. Therefore, in instrumental terms, these dialects are perceived as becoming less and less important. This also confirms that Mandarin and English have long taken on the role of the language of reference of the Chinese community in Singapore. 
$\mathrm{Ng}$ (2017) studied the attitudes of Singaporean Chinese dialect speakers towards the Speak Mandarin Campaign. His quantitative results (as well as his interview-based ones) allowed him to assert that most respondents have a positive attitude towards Mandarin, not only in term of usefulness, but also because it helps the Chinese community preserve its Chinese culture (Ng 2017: 62 ). His results led him to conclude that his participants hoped the SMC would continue. These results are interesting as they do not entirely corroborate our own results, missing out contradictory ideologies (Curdt-Christiansen 2016) and the possible criticisms and mixed feelings that some young Singaporeans feel nowadays. The objective of this article is precisely to investigate that point.

In two large scale studies investigating language maintenance and shift amongst university and polytechnic students (Siemund et al. 2014) as well as vocational training students (Leimgruber et al. 2018), language backgrounds, practices and attitudes were examined and analyzed. What was sought was the identification of the attitudes which students in those institutions displayed towards English, Singlish and their respective mother tongues. Positing that young postsecondary students are tomorrow's "social trendsetters" (Siemund at al. 2014: 360) in Singapore, Siemund et al. (2014) brought to light significant differences between the practices and attitudes of polytechnic students and their university counterparts. In conformity with the local normative pattern, the latter displayed more bilingual than multilingual practices, with English considered as a key language of Singapore.

In the same study, polytechnic students from Chinese backgrounds exhibited a greater tendency than university students for trilingualism, with English, their mother tongue and another Chinese vernacular being maintained and regularly spoken. Another remarkable result is the fact that contrary to these polytechnic students, university - i.e. elite - students also tended to regard Singlish as one of the fundamental traits of Singaporean identity (Siemund et al 2014: 357). In a follow-up on the previous study, Leimgruber et al. (2018) challenged the idea that the typical Singaporean is multilingual but rather that most repertoires are bilingual and trilingual. Their research led to similar results concerning the English-Mandarin bilingual proficiency of university students as compared with polytechnic and vocational schools students, especially in the Singaporean Chinese community. The relevance of these two studies also lie in the fact that national censuses never go into such detailed information on language practices and attitudes. This kind of statistical enquiries therefore enables the sociolinguistic community to obtain a more accurate picture of local language dynamics.

\section{The study and its population}

While acknowledging the relevance of current and previous investigations based on statistical data and attitudinal research, this article proposes a different kind of approach, although part of its inspiration draws upon its quantitative 
data, as our results confirm that both Singlish and Chinese dialects are important repertoires in the lives of the group of youths we investigated on (Forlot \& Chan 2017; Forlot 2018). Language policy perceptions are not construed here as socio-psychological categories, but as discursive ones. What it means is that in the analysis that follows, I have resorted to elicitation as one of the material traces (Heller et al. 2018) that was collected throughout the research. Elements of the interviews collected here are considered as discursive items of social actors who may feel free or constrained to speak out their minds, who may contradict themselves in the course of the conversations, or who might answer in ways converse to the stances they adopted in the questionnaires they filled out at an earlier stage of the research.

One of the perceived drawbacks of interviews is probably that the researcher has access mostly to what Silverstein (2003) called a reportive type of metalinguistic activity. This reportive type, as S. Tan (2012) puts it, corresponds to the explicit-evaluative content of given sociolinguistic discussions, which our research interviews actually purpoted to be. But preconscious language ideologies are also at play here, which means that the reportive type of metalinguistic activity, explicitly accessible via interviews, is inter-related to a reflexive one, itself articulated to some background knowledge activity shaping language-ideological presuppositions (Silverstein 1993). Interviews can then be looked upon as a site for the reproduction of language ideologies (Kroskrity 2000).

Overall, the ethnographic part of the research comprised 44 semi-structured interviews, of which 31 were done with undergraduate and graduate university students enrolled in various departments. Four interviews of primary and secondary teachers in their twenties or thirties were also organized, as well as seven interviews of university scholars involved in teaching and research in linguistics, Chinese studies, and Malay studies. Finally, two cultural figures of the Singapore Chinese community were interviewed as well.

Adopting a critical sociolinguistic stance (Heller et al. 2016; 2018), my goal in this article is to unveil young Singaporean adults' positionings vis-àvis language practices and policies. Therefore, I will focus more specifically here on students' discourses, collected in 2016 and 2017 on the campus of a prestigious Singapore university. For the sake of space, I selected excerpts from eleven of these interviews.

\section{Instrumentalizing and commodifying Singapore's languages}

In a present-day globalized economy, language has grown as a significant commodity. Heller (2010) describes the commodifying effect created by late capitalism on language, which has become not only a merchandize, but a resource with exchange value. Late modernity has created the possibility for the command of a language to be redefined from a talent or an inherent feature of a group to a measureable skill. The following sections will expand on this notion of language as a commodity in the case of Singapore's nation building. 


\section{Language for political stability}

One of the topics we discussed during our encounters with these young Singaporean students was how they perceived the political choices of their elders to opt for a policy of bilingualism and to maintain forms of racial assignation mostly inherited from British colonial rule. All of our participants expressed a clear understanding of the manners and the reasons the first rulers of independent Singapore managed diversity, and the reasons for these choices. For these youths, there was a necessity to stick to a system of racial divisions, not for segregation purposes but because it ensured equality and developed multiculturalism, if only a partitioned form of multiculturalism. In saying so, they are endorsing the decisions made by the founding fathers of the Republic.

Ahmad, a young Singaporean Malay, asserts that electing English as a common language was a good move for diplomatic reasons. To him, the overriding goal was to respect the balance between the ethnic groups in the territory. Note that he interestingly associates these ethnic groups with their languages, somewhat reifying the actual dynamics at play when Singapore became independent. This reminds us that in the narrative of the separation between Malaysia and Singapore in 1965, the issue of language and racial balance was one of the major bones of contention, the Singaporean leaders opposing Kuala Lumpur's planned policy of Malay racial precedence.

Except 1: Ahmad $(S-M)^{7}$

I think definitely a good move because I think that's one language that don't take priority and not a single mother tongue would take priority over the rest of the languages.

The argument developed above by Ahmad is also shared by all the Singaporean Chinese we interviewed. Two main reasons come up that justify supporting the decisions made by the elder leaders: the first one has to do with ethnic equality and neutrality of the state, an issue often construed as responsible for the divorce between Singapore and Malaysia in their shortlived merger, as evoked supra. The second reason is the rationality of the choice of English as a common language, for the same neutrality purposes but also for socioeconomic reasons.

\footnotetext{
7. All names have been changed. Some biographical elements on the eleven students quoted in this article are provided in the appendix. Respondents with Christian names were given replacement Christian names, and the same rule went for Chinese and Malay names. Apart for excerpt 1 (Ahmad is a Singaporean Malay, hence the acronym S-M) and although the corpus comprises informants from Malay, Indian and Mainland Chinese backgrounds, all the other excerpts come from the majority group of our study, i.e. Singaporean Chinese students (S-Ch). In the transcribed interviews, commas refer to short pauses. Unless mentioned otherwise, all interviews were led by me.
} 
To the question of whether it was a good move to opt for English as a common language when Singapore became independent in 1965, Christy and Dingdang reply the following:

\section{Excerpt 2: Christy (S-Ch)}

English, yeah definitely because it doesn't give any one race, ethnicity an advantage over the other. So everyone had to learn it. So it's like better I guess

\section{Excerpt 3: Dingdang (S-Ch)}

Well I think it's hard to say but probably it makes sense during that period of time since if they chose Chinese as a common language, it might cause some unhappiness among the Malays. If they chose Malay and the same thing goes for Chinese. English wise, I think it's also due to colonial history, that's why English was actually used. But ultimately I think it's okay, I mean English itself is a way to communicate. So well it's alright to use English as a common language to unify Singapore

The apparent oratory precautions they are taking when using "I guess", "it's hard to say" and "I think" are counterbalanced by more affirmative stances, as in "yeah definitely" or "so well it's alright." This fairly confident discourse on the fact that Singaporean leaders made the right decisions is hardly ever contradicted in our corpus of interviews when it comes to English. The acknowledgement of the place of this language in the world as early as the 1960s probably accounts for this position:

\section{Excerpt 4: Carol (S-Ch)}

I think it definitely was a good move [to choose English], because um, other than China, I think, most of the world would communicate in English even though it's not their inherent mother tongue but I think that it has slowly become like an international language (...) And just comparing to our neighbouring countries who chose to stick with, like, their mother tongues, like, our most neighbouring countries like Malaysia, I think that, um, English speaking, like comparing it, both countries, it was more economical because um business wise and everything (...) I don't know maybe I'm wrong but just comparing the two countries, I would think that it's the right move definitely because if we were to speak Chinese and our neighbouring countries were like Malay and everything we would have missed a lot of opportunities with them

Carol's reply is interesting inamuch as she resorts to the institutional term "mother tongue" twice in the excerpt, and if in the first instance, we can wonder whether she is speaking of the official Mother Tongues of the Singapore education system, the second instance confirms that she is using the term as a synomym for "native language" or "first language spoken in the family." This polysemic blurring of the terminology signals that in reflexive discourse and the language-ideological presuppositions it is backgrounded on, 
some official terms have made their way through commonsense understanding of the language dynamics at play.

One could then hypothesize that Carol perceives language learning as a clear-cut institutional process, with on the one hand a Mother Tongue and on the other hand additional languages, the former corresponding to the strict definition given by the state. This is somehow confirmed in her mentioning Chinese (i.e. Mandarin) as a plausible - but dismissed - choice of the common language for Singapore, despite the fact that three quarters of the Singaporean population are categorized as ethnically Chinese.

As in many other discourses collected along our fieldwork, the rationale for Singapore's language policies given by those young students reproduces the pragmatic vision of multilingualism as promoted by the first leaders, i.e. English for political and economic stability. Some participants are however keen on underlining the extent to which English and linguistic diversity seemed to be both assets and dangers for political stability in the early years of independence.

In excerpt 5, Amanda considers various reasons for opting for such a policy, including the political climate in the 1960 s, as well as the social inequalities that were hindering development. In an echo to Rubdy's reflexions on Singapore's ideology of meritocracy and the risks linked to the reproduction of inequality (Rubdy 2005: 66-70), Amanda also alludes to the difficulties of implementing such a policy and to the fact that some ethnic groups had a hard time abiding by it at first:

\section{Except 5: Amanda (S-Ch, Yr.3)}

I know why they chose English so like, it had to do with the kind of international climate at that time. They were really scared of communism. And then we were a colony, so it made a lot of sense to choose English (...) I mean I do think it was a good thing because I think after the initial period, like the fact that we speak English, as Singaporeans, in terms of just being able to find jobs (...) initially it was really, how do I say, it really divided people according to how educated they were, because that's why for example Indians were initially far more successful than the other races because they were mostly English-educated and they benefitted from this policy.

However, the neat distinction between English for unity and progress and the Mother Tongues for cultural maintenance and ethnic affiliation sometimes barely holds water in the opinions of these youths, as the following sections will show.

\section{Language homogeneization and survival at all costs}

Throughout the interviews, I tried to understand to what extent our respondents were aware of the risks induced by language and cultural homogeneization. An interesting outcome of these conversations is that none of these young students seemed to voice the hierarchizing, derogatory 
images post-independence Singaporean language engineering discourses have conveyed about the relations between Chinese Mandarin and Chinese dialects.

Ya $\mathrm{Li}$ explains below that besides the institutionalized languages she had access to in the education system (English, Mandarin, Japanese and French), she has been seeking to appropriate what she regards as her genuine family language, Cantonese, whose teaching was long banned in Singapore and is now available in scarce private or association classes.

\section{Excerpt 6: Ya Li (S-Ch-Interviewer 1: D. K. G. Chan. Int. 2: G. Forlot)}

Interviewer 1: You did Higher Chinese? [Higher Chinese = Mandarin for advanced students]

Ya Li: I did higher Chinese, then I did Japanese in secondary school.

Interviewer 2: At the Ministry of Education Language Centre?

Ya Li: Yeah for 4 years I did o-levels. But I never went for the proficiency test. Yeah it's one of the things that I want to go back and like get the proficiency test but I've never found the time to properly study for it. And also recently I'm trying to pick up Cantonese yeah because, my family's actually Cantonese. My father is Cantonese but my mother is Teochew, and, but I didn't grow up knowing Cantonese because you know of the, my father said because Lee Kuan Yew said that, yeah, dialects weren't useful so I never grow up learning Cantonese but recently I've been trying to pick it up yeah

Ya Li's testimony clearly shows the impact former Prime Minister Lee Kuan Yew's public opinions and instructions concerning the necessity to cast aside Chinese dialects had on her own family. It illustrates how some Singaporeans of her parents' generation complied with the no-dialect rule.

This does not mean that the youths we interviewed necessarily champion the idea that dialects should be taught or sustained publicly, but rather that those languages are part of their heritage as Chinese Singaporeans, that they belonged to their parents or grand-parents, and therefore that to some extent they form a part of these young Singaporeans' identities too. In fact, most respondents do not share the rather brutally diglossic policy of phasing out dialects in favour of Mandarin, even though they understand that for pragmatic reasons, something had to be done for the unity of the Chinese community. For instance, in the following extract, Maya expresses sadness that dialects have been declining, but explains that it had to be done for the sake of the country's survival:

\section{Excerpt 7: Maya (S-Ch)}

Singapore sort of like, just, um, assimilates people, like okay if they're Chinese, it doesn't matter like what dialect group you're from, you learn Mandarin, you know? Yeah so it's like the loss of dialects but, $\mathrm{mmm}$, sociologically and culturally probably that, there are definitely losses like in terms of culture and now, because we're so economically developed already, then I think that, because we have these like comforts, that's why we can look back and say that, oh, um, our culture was lost at that time, 
but if we project ourselves like into the past right, I think if I don't even have enough like, food or like economic stability, I wouldn't be complaining about what language I speak, I'll just want to like survive.

\section{Language for economic growth}

I will not dwell on what was developed above on the obvious economic value of English as a commodity in the globalized economy on which Singapore vigourously embarked in the years following independence. Wee (2003; 2006) aptly reminds us that languages in Singapore have since then been the object of instrumentalism and this is particularly true in the case of the opposition between Chinese Mandarin and dialects.

If Asian values and familial bond had been at the centre of the PAP leaders' concern, then adopting Mandarin as an ethnic language probably made little sense, as the vast majority of Chinese Singaporeans had ancestral ties with Southern Chinese regions. In fact, opting for Mandarin also had to do with setting store by the economic growth of China's market economy, and Mandarin soon became "intertwined with, rather than separate from, economic gains" (Wee 2006: 353). A language such as Mandarin, besides its ethnocultural, besides their ethnocultural (the link to Chineseness) and political (the necessity for stability within the Chinese community) motivations, was ranked favourably "based on a criteria of utility, in this case, perceived economic value" (Tan 2012: 345).

The Government actually never tried to conceal this, as the excerpts from Lee Kuan Yew and Chee Hong Tat quoted above are witness of. Public state discourse has always foregrounded the virtue of Mandarin in order to connect with the outside Chinese world and to connect with China itself for more than just patrimonial reasons. This argument seems to have hit home for Chinese Singaporeans, as Amanda reports her experience as a pupil and listener of Singapore's official discourse:

\section{Excerpt 8: Amanda (S-Ch)}

I think with Mandarin or with Chinese dialects, it gets a bit more complicated because there is the whole question of practicality which the government has repeated over and over again (...) with Mandarin, there is the idea of heritage, and that there's the additional really strong idea that this is going to be really useful and you should, just learn it because of China.

Amanda recalls the point hammered home by the state that Mandarin should serve both as patrimonial marker as well as a potential to reach out to the Mandarin-speaking business world. In a context of late modernity which foregrounds the economy as one of the driving forces of state policies, with languages being part and parcel of the latter, the business value of practicing or learning a language has to make do with - and sometimes clashes with - the 
ethnic or cultural construals politicians and citizens in general have of languages as homogeneous and impermeable entities (Blackledge \& Creese 2008).

A good example of this is to be found within the Indian community of Singapore. Faced with a more flexible Mother Tongue policy initiated in the 1990s allowing Indian pupils to chose a non-Tamil Indian language in school, families have nevertheless had the tendency to favour Hindi as a Mother Tongue over the Indian languages of their ancestral groups, as the national language of India is often valued as a more certain asset in a transnational and transmigrant perspective (Jain \& Wee 2017; Jain 2021).

\section{(Dis)connecting language and ethnic identity}

\section{Language and political control}

One the objectives of the present research was to investigate the extent to which young educated Singaporeans would engage in a non-essentialist discourse as far as languages are concerned in a country which built a great part of its stability on a primordialist form of ethno-linguistic equilibrium. We did not ask the question explicitly, as we knew that our participants were likely to try to accommodate to the assertions or questions of the interviewers. Therefore, as expected, most of the initial answers related, described and most of the time justified the classical CMIO ethnocultural division system (cf. supra), somehow reproducing the official discourse that generated the contemporary Singapore national narrative.

A few of the students nevertheless demonstrated some awareness of the ideological foundations of their own discourse, acquired throughout their education. Here is what Florence ('okay I'm not sure it's because we were taught this but...') and Amanda (I think it's also part of like, control ?) had to say when they were asked to comment on the ways languages were chosen and assigned to different groups by the first rulers of the city-state:

\section{Excerpt 9: Florence (S-Ch)}

Yeah I mean like I think honestly, okay, I'm not sure it's because we were taught this but like, I think it was good, because it did, it was necessary, because otherwise it was going to have like a very difficult like, three separate cultures and then you're going to have to like, the communication won't be there, it won't be as efficient so English was like the most, like something that none of them had in common so just make one the center and then to keep your ethnicity, you had your mother tongue for that.

\section{Excerpt 10: Amanda (S-Ch)}

I don't think it's as simple or as straightforward as Chinese is your heritage. I think it's also part of, like control? Like they think that certain categories of people, like, well they split us up into races right. So then you have Chinese people who 
should speak Chinese just because, and you have Tamils who should speak Tamil and then you have other Indians who should speak um or whatever. So I don't know, I think, because I mean otherwise, a lot of people would be able to learn the language any way I think within the house, or with relatives or going for external classes. I don't know actually.

In addition to the political awareness that emerges in some of these narratives, let us note that the question of justifying the choice of Mandarin as a mother tongue for all Chinese students made some respondents hesitate, or express some level of unease. The repetition of "I don't know" in Amanda's response (excerpt 10) illustrates this hesitation. Maya's answer in excerpt 11 also betrays well this discursive phenomenon, as she wavers a while before mentioning the issue of the state's political control:

Excerpt 11: Maya (S-Ch)

Maya: so we just don't speak Chinese [in my family], Mandarin, and my grandmother speaks like dialect, Canto, Cantonese. So, like, instead of speaking Mandarin we speak Cantonese more. Yeah, so Mandarin just doesn't really like, I don't feel that there's a need to speak in Mandarin. But neither do I feel like, I cannot. Like if I want to, I can, they understand me. It's just that they're probably not a very good at like the technical aspects of it.

Interviewer: Mmm yes, so isn't that kind of weird that your Mother Tongue should actually not be, the language you're really speaking in your heritage? You see what I mean? That is to say they told you your language which is supposed to be, what, Mandarin, which was supposed to be the language of your, cultural background but in fact your cultural background was not in Mandarin. So what do you think of that?

Maya: Um (silence)

Interviewer: As in fact you spoke two versions, two Chinese languages, Cantonese right? And

Maya: Mandarin yeah.

Interviewer: And Mandarin.

Maya: I, okay, this like goes back into state instruments of political control.

As noted so far, a number of respondents are conscious that the choice of Mandarin for the Singapore Chinese communities was probably as much a political and economic move as a merely cultural enterprise. This sometimes raises the double issue, for some of the participants, of Chineseness in presentday, globalized Singapore and of Mandarin as a legitimate vehicle of Chineseness.

\section{Mandarin, dialects and Chineseness in Singapore}

The issue of Chineseness has attracted some scholarly attention in the past decades, although little research has specifically focused on the role of language in the development and shift of ethnicities and identities in the Chinese diasporas in Asia. Wong \& Tan (2017b), whose investigation compares attitudes among the Chinese communities of Singapore, Malaysia and the PRC, do mention some research carried out earlier in Malaysia (Low et al. 2010) or Singapore with 
regard to specific dialect groups (Gupta \& Yeok 1995) (Gupta \& Yeok 1995). Some work on the way Chinese Singaporeans perceive language in relation to their identity and to the construction of their Chineseness has been published in recent years as well (Tan 2012 and Ang 2017).

It comes as little surprise that most studies of overseas Chinese communities attest to a tendency of language shift towards the local languages. In the case of Singapore and Malaysia, the complexity comes from the presence of English and/or Malay as national or official languages, the dominance of Mandarin as a common language and the gradual decline of Chinese vernaculars traditionally used by the older generations. As most of our interviewees were Chinese (i.e. from Chinese descent or for three of them, migrated from Mainland China or Malaysia when they were younger), we attempted to capture what sense it made for them, in a globalized timespace, to be assigned and to adopt or assert an identity as Chinese. We wanted to understand what language(s) entailed being Chinese, and how connected Chineseness was with Singaporeanness.

As developed above, the phasing out of dialects has created the expected effect of propelling Mandarin as the major Chinese language in Singapore nowadays. Our respondents are cognizant of this fact and of the professional asset it procures those who have a good command of standard Chinese. But for them, this situation has generated if not language loss - as elderly Singaporeans continue speaking Hokkien, Cantonese and Teochew mostly ${ }^{8}-$ but language shift within their own families. William's and John's testimonies are significant illustrations of this:

\section{Excerpt 12: William (S-Ch.)}

Now I can barely speak to my grandmother because she speaks Cantonese, I think it's a bit isolating for her, and for me (...) I don't recall the time when I could step out of my house and you'd hear all sorts of dialects, the kind of fluency my grandparents had, I don't get that when I'm outside.

\section{Excerpt 13: John (S-Ch. - Interviewer 1: D. K. G. Chan-Int. 2: G. Forlot)}

Interviewer 1: How do you feel about yourself mastering Teochew?

John: Myself not speaking it.

Int. 2: Yeah you speak Teochew to your grandmother, but you're not so comfortable compared with Mandarin?

John: No as in like I'm not comfortable speaking to my parents in Teochew when they try.

Int. 1: Yeah so how do you feel about that, dialects being, disappearing from the scene?

8. This has of course not gone unnoticed by the Singapore Government and Chinese dialects regularly resurface during electoral campaigns or health crises in order to reach out to the elderly (Lim 2015). For instance, Hokkien, Cantonese and Teochew were unrelunctantly used in the media during the 2002 SARS epidemic and the 20202021 COVID-19 pandemic. 
John: I think it's a pity but other than that I think like, it's just, because of the Government policy and things, one must speak Mandarin, just, I find it a bit of a pity.

What the latter extract shares with William's is the issue of language shift and the intergenerational disruption it has created within families. These two young men now have difficulty interacting with their own grandmothers. A rescaling of Mandarin in Singapore's linguistic landscape has gradually taken shape. Originally engineered, like Tamil and Malay, as the language imposed for the maintenance of Chineseness and more generally Asian values, Mandarin has conversely generated a different kind of attachment, quite remote from authenticity and familial Asian values: those of Chinese globalization, socioeconomic success and international business.

Meanwhile, Mandarin as a collective language of Chinese Singaporeans, only accessible via Mother Tongue education and therefore unattainable by the elderly, has created a breach in intrafamilial communication, with grandchildren unable to interact easily with their grandparents or elderly people in general, while the latter are paradoxically often seen as the custodians of Chinese traditions. This is why the rise of Mandarin as the flagship of Singaporean Chineseness is met with some wariness by our participants.

All this may account for the wavering discourses on Chinese identity among the youths we interviewed. Let us remember however that they are considered as elite students, anglo-dominant for almost all of them. As revealed in Siemund et al. (2014), Leimgruber et al. (2018) and other parts of our own research (Forlot \& Chan 2017; Forlot 2018), university students tend to value English and Singlish within their language repertoires. When asked to position themselves with regard to language practice and their feeling of Chineseness, all of them take for granted that they are ethnically Chinese, but the very fact that English and Singlish are the dominant language forms they use on a daily basis bears witness to their Singaporean specificity, as Jessica points out in the following excerpt:

\section{Excerpt 14: Jessica (S-Ch)}

Interviewer: how do you feel about being of Chinese extraction and not being so comfortable in the Chinese language or a Chinese dialect?

Jessica: I think when I was younger I didn't really mind, because like I don't really feel very Chinese in any way. I mean we're Singaporean Chinese, but typically in Singapore like, we're known as multiracial but really it's like kind of like it isn't a strong factor because it's not a divisive factor. Like you don't identify with it as much or at least that's how I feel. So it didn't really matter because English is, kind of like the most widely used language anyway. I guess now, I do feel it's a bit more important because, I mean, like there's the older generation like, you speak to your random aunties on the street or like, to your grandparents and you can't connect with them, so that's also quite a big part of the heritage I think. So, I'm not sure about the Chinese part as separate from the Singaporean part though, I don't think that Singaporean Chinese come together like there's no separate Chinese identity. 
Interestingly enough, Jessica points to the fact that the "generation gap" she mentions is created by a missing language link, which she identifies as the Chinese language (be it Mandarin or a dialect). She also sees her Chineseness as part of her identity, but not specifically Mandarin as a foundational part of it, as she mentions earlier in her interview that Mandarin as an imposed school and home language "was an experiment that failed on [her]."

The family failure brought forward by Jessica is also certainly that of the Singapore education system in which Mandarin as a Mother Tongue was imposed in ways most of our participants disapprove of as dull, monotonous, tedious or even "tyrannical" (in our interviewee William's own words). This education-related aspect of the elaboration of Singapore Chineseness, though beyond the scope of this article, is probably of paramount importance in grasping how Singaporean Chineseness has redefined itself differently from other kinds of overseas communities and along the lines of Singapore's multicultural and English-knowing (Pakir 1992) fabric. Irresolute as to what it is to be Chinese, Amanda expresses it in uncertain terms:

\section{Excerpt 15: Amanda (S-Ch)}

I do think that actually the place we live, to me that's like home, it isn't to me really about your ethnic background but just kind of, environmental culture you grew up in. But despite knowing that in my brain, like I guess I do feel emotionally that, like I would like to have that link to my ethnic background even though I would never want to work in China, you know, or I would, like in many ways, I don't feel affiliated to being a Chinese person, but, yeah I want to speak Cantonese, I want to speak Mandarin.

\section{Conclusion}

This article contended to bring to light several aspects of language-inidentity issues. Our fieldwork also gave an opportunity to these university students, who are thought to be the country's future elite, to reflect upon the foundation of Singapore as a late modern society and as a strong economic actor in the region. The interviews evince the extent to which those youths understand language(s) as practices, policies and therefore ideologies, and consequently as tools or means for political stability and social control.

Furthermore, while mostly focussing on the Chinese population amidst our interviewees, the research shows that their stands on Chineseness are much more complex than what the state has tried to concretize as an ethnolinguistic sense of belonging. Though the interviews reveal that the participants conceive the state policies as essentialist and possibly unfit for a late modern, globalized society, they overall justify their elders' opting for strong-willed measures regarding language and ethnic balance. Although this appears to bring unchallenged grist to the mill of the early leaders of Singapore, what 
the narratives really show is that the young elite students we interviewed are aware that promoting state stability and economic success was done thanks to the imposition of English and homogeneously construed Mother Tongues, and that these policies were implemented at the expense of local vernaculars, thus creating regrettable cultural loss and language shifts within their families. What still needs to be identified regarding the above-mentioned issues is whether they are sociologically determined, in other words whether other discourses would emerge among different age or class groups, as some quantitative investigations seem to indicate (Siemund et al. 2014; Leimgruber et al. 2018).

What this research shows after all is that with its multicultural and multilingual fabric, Singaporean society cannot but be analyzed in complex terms, with all historical, linguistic, educational, economic and identificational ideologies at play. For instance, school is the locus in which social and linguistic norms are instilled, and as such, the place where children interact and develop - despite normative pressure - the two kinds of Englishes which are spoken at all levels of society: Standard English and its local, nativized colloquial and often controversial counterpart, Singlish. How all this contributes to the molding of Singaporean identities - and ethnicities if one decides to retain this concept - still deserves further research and analysis.

\section{Bibliography}

Ager, D. E. 2005. "Image and Prestige Planning." Current Issues in Language Planning 6/1. 1-43.

Ang, S. 2017. "I am More Chinese than You: Online Narratives of Locals and Migrants in Singapore." Cultural Studies Review 23/1. 102-117.

Blackledge, A. \& Creese, A. 2008. "Contesting 'language' as 'heritage': Negotiation of identities in late modernity." Applied Linguistics 29. 533-554.

Bokhorst-Heng, W. 1998. "Language planning and management in Singapore." In Foley J. A. et al. (eds.) English in New Cultural Contexts: Reflections from Singapore. Singapore: Oxford University Press. 287-309.

Bokhorst-Heng, W. 1999. "Singapore's Speak Mandarin Campaign: Language ideological debates in the imaginings of the nation." In Blommaert, J. (ed.). Language Ideological Debates. Berlin \& New York: De Gruyter. 235-265.

Bolton, K. et Ng, B. C. 2014, "The dynamics of multilingualism in contemporary Singapore", World Englishes 33/3. 307-318.

Bourdieu, P. 1991. Language and Symbolic Power. Cambridge, MA: Harvard University Press.

Cavallaro, F. \& Ng, B. C. 2009. "Between status and solidarity in Singapore.” World Englishes 28/2. 143-159.

Cavallaro, F. \& Serwe S. K. 2010. "Language use and language shift among the Malays in Singapore." Applied Linguistics 01/2010. 129-169.

Cavallaro, F., Seilhamer, M. F., Ho, Y. Y., Ng, B. C. 2018. "Attitudes to Mandarin Chinese Varieties in Singapore." Journal of Asian Pacific Communication 28/2. 195-225.

Chew, G.-L. P. 2013. A Sociolinguistic History of Early Identities in Singapore. From Colonialism to Nationalism. Basingstoke, Palgrave Macmillan.

Chua, B. H. 1995. Communitarian Ideology and Democracy in Singapore. London: Routledge. 
Curdt-Christiansen, X. L. 2014. "Planning for Development or Decline? Education Policy for Chinese Language in Singapore." Critical Inquiry in Language Studies 11/1. 1-26.

Curdt-Christiansen, X. L. 2016. "Conflicting language ideologies and contradictory language practices in Singaporean multilingual families." Journal of Multilingual and Multicultural Development 37/7, 694-709.

Da Silva, A., McLaughlin, M. \& Richards, M. et al. 2007. "The globalized new economy: The commodification of bilingualism and the emergence of the language worker." In Heller, M. (ed.) Bilingualism: A Social Approach. London: Macmillan. 183-206.

Forlot, G., 2018. "Pratiques linguistiques et 'multilinguisme pragmatique': 50 ans de glottopolitique à Singapour." Glottopol 30. 34-62.

Forlot, G. \& Chan D. K. G. 2017. "From Pragmatic Multilingualism to Insecure Plurilingualism. Language Learning and National Narrative in Contemporary Singapore." International Symposium on Bilingualism 11, University of Limerick, Ireland. June 12, 2017.

George, C. 2007. "Consolidating authoritarian rule: Calibrated coercion in Singapore." The Pacific Review 20/2. 127-145.

Giddens, A. 1990. The Consequences of Modernity. Cambridge: Polity Press.

Gupta, A. F. 2008. "The language ecology of Singapore." In. Creese, A., Martin, P. \& Hornberger, N. (eds.) Ecology of Language. New York: Springer. 99-112.

Gupta, A. F. \& Yeok, S. P. 1995. "Language shift in a Singapore family.” Journal of Multilingual and Multicultural Development 16/4. 301-314.

Heller, M. 2010. "The commodification of Language." Annual review of Anthropology 39. 101-114.

Heller, M., Pietikäinen, S. \& Pujolar, J. 2018. Critical Sociolinguistic Research Methods. Studying Language Issues That Matter. New York \& London: Routledge.

Heller, M., Bell, L. A., Develuy, M., McLaughlin, M., Noël, H. 2016. Sustaining the Nation. The Making and Moving of Language and Nation. Oxford: Oxford Univesity Press.

Ho, C. L. \& Alsagoff, L. 1998. "English as the common language in multicultural Singapore." In Foley, J.A. et al. (eds.) English in New Cultural Contexts: Reflections from Singapore. Singapore: Oxford University Press. 201-207.

Jain, R. 2021. "The other mother tongues of Singaporean Indians." In Jain, R. (ed.) Multilingual Singapore: language policies and linguistic realities. London \& New York: Routledge. 65-84.

Jain, R. \& Wee, L. 2017. "Cartographic mismatches and language policy: the case of Hindi In Singapore." Language Policy 17. 99-118.

Jain R. \& Wee, L. 2018. "Diversity management and the presumptive universality of categories: the case of the Indians in Singapore." Current Issues in Language Planning 20/1. 16-32.

Kamwangalu, Nkonko M. 1992. "Mulilingualism and Social Identity in Singapore." Journal of Asian Pacific Communication 3 (1). 33-47.

Kroskrity, P. 2000. "Regimenting languages: Language ideological perspectives.” In Kroskrity, P. (ed.). Regimes of Language. Santa Fe: School of American Research. 1-34.

Lee, K. Y. 2011. My Lifelong Challenge: Singapore's bilingual journey. Singapore: Straits Times Press.

Leimgruber, J.R.E. 2013. Singapore English. Structure, Variation, and Usage. Cambridge: Cambridge University Press.

Leimgruber, J.R.E., Siemund, P. \& Terassa, L. 2018. "Singaporean students' language repertoires and attitudes revisited." World Englishes 37.2: 282-306. 
Li, W., Saravan, V. \& Ng. J. 1997. "Language shift in the Teochew community in Singapore: A family domain analysis." Journal of Multilingual and Multicultural Development 18. 364-384.

Liew, K. K. 2015. “'I am Limpeh !.’ Parodying Hegemony, Anti-Nostalgic Cultural Insurgency and the Visual Amplification of Lee Kuan Yew in Late Authoritarian Singapore." Journal of Creative Communications 10/1.21-38.

Lim, L., 2009, "Beyond fear and loathing in SG. The real mother tongues and languages policies in multilingual Singapore." AILA Review 23. 52-71.

Lim, L. 2010. "Migrants and 'mother tongues': Extralinguistic forces in the ecology of English in Singapore.” In Lim, L., Pakir, A. \& Wee, L. English in Singapore. Modernity and Management. Hong Kong: Hong Kong University Press. 19-54.

Lim, L. 2015. "Coming of age, coming full circle: The (re)positioning of (Singapore) English and multilingualism in Singapore at 50." Asian Englishes 17/3. 261-270.

Lim, L., Pakir, A. \& Wee, L. (eds). 2010. English in Singapore. Modernity and Management, Hong Kong, Hong Kong University Press.

Low H. M., Nicholas H. \& Wales R. 2010. "A sociolinguistic profile of 100 mothers from middle to upper-middle socio-economic backgrounds in Penang-Chinese community: what languages do they speak at home with their children." Journal of Multilingual \& Multicultural Development 31/6. 569-584.

Ng, P.C.L. 2017. A Study of Attitudes of Dialect Speakers Towards the Speak Mandarin Campaign in Singapore. New York: Springer.

Ng, B. C. \& Cavallaro, F. 2019. "Multilingualism in Southeast Asia: The Post-Colonial Language Stories of Hong-Kong, Malaysia and Singapore." In Montanari, S. \& Quay, S. (eds.) Multidisciplinary Perspectives on Multilingualism: The Fundamentals. Berlin: Mouton De Gruyter. 27-50.

Pakir, A., 1992. "English-knowing bilingualism in Singapore.” In Ban, K.C. Pakir, A. \& Tong C. K. (eds) Imagining Singapore. Singapore: Times Academic Press. 234-262.

Platt, J. \& Weber, H., 1980, English in Singapore and Malaysia: Status, Features, Functions, Kuala Lumpur: Oxford University Press.

Rubdy, R., 2005, "Remaking Singapore for the New Age: Official Ideology and Realities of Practice in Language-in-Education." In Lin, A.M.Y. et Martin, P.W., Decolonisation, Globalisation. Language-in-Education Policy and Practice. Clevedon: Multilingual Matters. 55-73.

Rubdy, R. 2001. "Creative destruction: Singapore's Speak Good English Movement.” World Englishes 20. 341-355.

Siddique, S. 1990. "The phenomenology of ethnicity: A Singapore case study." Sojourn 5. 35-62.

Siemund, P., Schulz, M.E. \& Schweinberger, M. 2014. "Studying the linguistic ecology of Singapore: A comparison of college and university students." World Englishes 33/3. 340-362.

Silverstein, M. 1993. "Metapragmatic discourse and metapragmatic function." In Lucy J. A. (ed.). Reflexive Language: Reported Speech and Metapramatics. Cambrige: Cambridge University Press. 33-58.

Silverstein, M. 2003. "Indexical order and the dialectics of sociolinguistic life." Language and Communication 23, 193-229.

Sim, J. 2019. “'But you don’t sound Malay!' Language dominance and variation in the accents of English-Malay bilinguals in Singapore." English World-Wide 40/1. 79-108.

Stroud, C. \& Wee, L. 2007. "Consuming identities: Language planning and policy in Singaporean late modernity." Language Policy 6. 253-279. 
Stroud, C. \& Wee, L. 2012. Style, Identity and Literacy. English in Singapore. Bristol: Multilingual Matters.

Tan, E. 2007, "The Multilingual State in Search of the Nation: The Language Policy and Discourse in Singapore's Nation-Building." In Lee, H.G. \& Suryadinata, L. (eds). Language, Nation and Development in Southeast Asia. Singapore: ISEAS. 74-117.

Tan S. 2012. "Language ideology in discourses of resistance to dominant hierarchies of linguistic worth: Mandarin Chinese and Chinese 'dialects' in Singapore." The Australian Journal of Anthropology 23. 340-356.

Tan, Y.-Y., 2014. "English as a 'mother tongue' in contemporary Singapore." World Englishes 33/3. 319-339.

Tan, Y.-Y. 2017. "Singlish: An illegitimate conception in Singapore's language policies?" European Journal of Language Policy 9/1. 85-103.

Tupas, R. 2015. "Pragmatism, Mandarin and political culture in Singapore: recent reprises of an ideology." Journal of World Languages 2 (2-3): 94-105.

Turnbull, C.M. 2009. A History of Modern Singapore 1819-2005. Singapore, NUS Press.

Vaish, V., Jamaludeen, A. \& Roslan, M. 2009. "The Sociolinguistic Survey of Singapore 2006. Findings anf Policy Implications." Research Brief No. 09-001. Singapore: National Institute of Education.

Weatherall, A., Watson, B. M., \& Gallois, C. (eds.). 2007. Language, discourse and social psychology. New York: Palgrave Macmillan.

Wee, L. 2002. "When English is not a mother tongue: Linguistic ownership and the Eurasian community in Singapore." Journal of Multilingual and Multicultural Development 23/4. 282-295.

Wee, L. 2003. "Linguistic instrumentalism in Singapore." Journal of Multilingual and Multicultural Development 24/3. 211-224.

Wee, L. 2005. "Intra-Language Discrimination and Linguistic Human Rights: The Case of Singlish", Applied Linguistics 26/1. 48-69.

Wee, L. 2006. "The semiotics of language ideologies in Singapore." Journal of Sociolinguistics 10. 344-361.

Wee, L. 2018. The Singlish Controversy. Language, Culture and Identity in a Globalizing World. Cambridge, Cambridge University Press.

Wong, K. Z.-H. \& Tan, Y.-Y. 2017a. "Mandarinization and the construction of Chinese ethnicity in Singapore." Chinese Language and Discourse 8/1. 18-50.

Wong, K. Z.-H. \& Tan, Y.-Y. 2017b. "Being Chinese in a global context: Linguistic constructions of Chinese ethnicity." Global Chinese 3/1. 1-23.

Wong, W. K. 2011. Census of Population 2010. Singapore: Department of Statistics.

Xu, D., Chew, C. H., \& Chen, S. 1998. "Language use and language attitudes in the Singapore Chinese community." In Gopinathan, S., Pakir, A., Ho, W. K., Saravanan, V. (eds) Language, Society and Education in Singapore. Singapore: Times Academic Press. 133-155. 


\section{Appendix 1:}

Notes on the acronyms and on some terms:

- SAP school: Also called "Higher Chinese", the Special Assistance Plan caters to students whose results in Mandarin are the highest.

- MOELC: The Ministry of Education Language Centre, a two-campus special centre for the learning of foreign languages (i.e third languages, including Japanese, German, French, Arabic, Indonesian and Spanish). Courses take place after regular classes and are theoretically reserved for the top students of each school.

- Chinese: When it refers to the language, Chinese has the same meaning as Mandarin in this article.

- Mother Tongue: this term is to be understood here as the Asian language which pupils are to take at school in Singapore, based of the ethnic affiliation indicated on the identity card. Chinese Singaporeans learn Mandarin, Malay Singaporeans learn Malay, and Indian Singaporeans learn an Indian language (either Tamil or a non-Tamil language - i.e. Hindi, Bengali, Punjabi, Urdu or Gujarati).

\section{Appendix 2: \\ Biographical elements on the interviewees (in alphabetical order):}

Ahmad: Second year male student, Malay Singaporean. Studies Political Science.

Ahmad was born in Singapore in a Malay-speaking family. He and most of his relatives still speak Malay at home and in the community. His Mother Tongue was Malay. He thinks that English is his stronger language for formal situations, but that his proficiency in Malay is high as well. He learned Mandarin for a couple of years at school, and started French at university. He would like to take German and Spanish in the future.

Amanda: Fourth year female student, Chinese Singaporean. Started in computer science in year 1 but switched to a major in European studies, with a minor in sociology. 
Amanda was born in Singapore of Cantonese-speaking Malaysian parents. Her parents spoke only Cantonese at home, had some fluency in Malay and also spoke some English at home. She only interacted with them and her siblings in English. Her mother tongue was Mandarin, but she disliked it very much and hardly uses it now. She studied Korean for a couple of years at school, as well as a bit of Malay which she would like to learn more now, in particular with her father. She took three years of French at university. She says that she uses Singlish daily.

Carol: Second year female student, Chinese Singaporean. Studies biology.

Carol says that she was brought up entirely in English, although Cantonese was used at her grandparents' or great aunts' houses. No one at home was proficient in Mandarin, and she herself had low results at school in her Mandarin Mother Tongue classes. She indicates that she ought to study Chinese, but that she has never really liked it. She has taken French at university for two semesters and intends to continue studying it. She says she uses Singlish daily, which she claims is her most "natural" language.

Christy: Third year female student, Chinese Singaporean. Majoring in Global Studies, with a specialty in international communication.

At home, she speaks both English and Chinese, and her mother also interacts in Cantonese and Hokkien. She is quite fluent in Mandarin as she took the SAP school programme. She briefly studied Japanese in high school, and French at university. She spent a year abroad in Reims, France. She is interested in languages and likes to find the connections between them (eg. Chinese and Japanese writing systems or French and English grammars). She says that she uses Singlish on a daily basis.

Dingdang: Second year female student, Chinese Singaporean. Majoring in Global Studies, with a specialty in business and transnational culture.

After high school, she enrolled in a polytechnic before being admitted into university. She was born in Singapore in a Hainanese and Teochew family. Her paternal grandparents spoke Hainanese and she developed some limited comprehension skills of it. Outside her mother, her maternal relatives live in Malaysia and they speak Teochew and some Malay. She herself declares that she knows some Teochew, but that she is more fluent in Mandarin, which was her school Mother Tongue and which she speaks at home with her Chinese-educated mother. She says that her favorite language is Mandarin, but that overall her skills are higher in English, in particular when it comes to writing. In informal situations, she indicates that she speaks Singlish, but in her opinion, it is not a language, but just a variety with elements from other languages in it. In addition, she studied 
some Japanese and has been taking French at university.

Florence: Third year female student, Chinese Singaporean. Majoring in Psychology.

Her main language is English. Both her Singapore-born parents speak Mandarin, but her mother has some basic knowledge of Cantonese. Her paternal grandparents are Teochew and Hakka and speak both languages. However family interactions are most of the time in Mandarin. She learned Chinese as a mother tongue but considers herself very westernized, claiming that English is her strongest language. She indicates that she often speaks Singlish, which she regards as a creole. She learned French for two years at university.

Jessica: Third year female student, Chinese Singaporean. Studies English Literature.

She was born in Singapore of a Teochew mother and a Hokkien father, both born and raised in Singapore. The language of communication at home has mostly been English, but dialects are generally used with the grandparents. She says that she does not speak much to her grandparents because of the language barrier. She indicates that her proficiency in Mandarin is basic, although she took Higher Chinese as a mother tongue at school. She is currently learning French, and says she uses Singlish in all informal situations. Due to her studies, she has a good metalinguistic and theoretical knowledge of the ways languages work.

John: Fourth year male student, Chinese Singaporean. Majoring in Geography.

He was raised in Singapore from a Singapore-born Teochew father and a Malaysia-born Teochew mother who both spoke Mandarin at home with their children. He has some limited knowledge of Teochew but feels much more comfortable in Mandarin (which was his Mother Tongue) and English. He feels quite insecure with his Mandarin if compared to that of Mainland Chinese students. He learned Korean in a private school, and basic Malay and French in the first two years of university. He indicates that he speaks Singlish on a daily basis, but considers it as nothing more than an informal dialect of English.

Maya: First year female student, Chinese Singaporean. Majoring in Political Science.

She was raised in a mainly English-speaking Singaporean Cantonese and Teochew family where Cantonese was spoken with the paternal 
grandparents. She says she used Mandarin to communicate with her Teochew-speaking mother's relatives. She considers herself bilingual in English and Chinese, as she learned Mandarin as a mother tongue in a SAP school, but thinks that Malay should be a requirement for all Singaporeans. She attended MOELC classes in Japanese and has been taking French at university. She however indicates that her main language in daily life, except in formal situations, is Singlish.

William: Master's degree male student, Chinese Singaporean. Studies philosophy.

Born in Singapore in a Cantonese-speaking family, William indicates that English is by far his strongest language and that he took Chinese as a Mother Tongue at school. He says he disliked it and that he would have liked to be proficient in Cantonese to be able to interact with his grandparents. He has been learning French and also took some German in the past. He speaks Singlish on a daily basis, which he considers is the informal language of most Singaporeans.

Ya Li: First year female student, Chinese Singaporean. Studies at the Faculty of Science.

Raised in a Cantonese-Teochew family, she says that only Mandarin and English were spoken at home. She took Higher Chinese as a Mother Tongue in one of Singapore's most prestigious secondary schools. She now mainly speaks English and says she has forgotten most of her Mandarin. She has studied other languages such as French, Japanese and Thai. She indicates that she uses Singlish on a daily basis. 
